\title{
PROSES AKTIVASI ARANG KAYU LABAN (Vitex pinnata L) DENGAN CARA PEMANASAN PADA SUHU TINGGI
}

\section{Activation Process of Laban's Wood (Vitex pinnata L) Charcoal Through High Temperature Heating}

\author{
Kasmawarni \\ Pusat Standardisasi Industri \\ Jalan Gatot Subroto Kav. 52-53, Lt. 20 Jakarta 12950. \\ e-mail: kas rose57@yahoo.com
}

Diterima: 3 September 2013, revisi akhir: 27 September 2013 dan disetujui untuk diterbitkan: 3 Oktober 2013

\begin{abstract}
ABSTRAK
Penelitian proses aktivasi arang kayu laban (Vitex pinnata $L$ ) dengan cara pemanasan pada suhu tinggi telah dilakukan. Tujuan penelitian adalah untuk mendapatkan kondisi suhu dan waktu aktivasi yang baik agar dapat dihasilkan arang aktif yang bermutu memenuhi persyaratan standar. Penelitian dilaksanakan menggunakan rancangan acak lengkap dengan percobaan faktorial. Suhu dan waktu aktivasi adalah faktor perlakuan yang diterapkan. Faktor suhu (A) terdiri dari 4 perlakuan, yaitu $700,800,900$, dan $1000^{\circ} \mathrm{C}$, sedangkan faktor waktu (B) meliputi 1, 2, 3, dan 4 jam. Adapun pengujian yang dilakukan terdiri dari daya serap lodium, kadar air, dan kadar abu. Hasil penelitian menunjukkan bahwa cara aktivasi arang kayu laban (Vitex pinnata $L$ ) menggunakan suhu tinggi yang cukup baik adalah aktivasi suhu $800^{\circ} \mathrm{C}$ selama 4 jam. Cara aktivasi ini dapat menghasilkan mutu arang aktif kayu laban yang memenuhi persyaratan standar SNI 06-3730-1995 dengan daya serap lodium sebesar 806,00 mg/g, kadar air sebesar 0,82 persen dan kadar abu sebesar 1,35 persen.
\end{abstract}

\section{Kata Kunci : Aktivasi arang, arang aktif, kayu laban}

\begin{abstract}
It had been done a research about activation process of Laban's (Vitex pinnata $L$ ) wood charcoal through high temperature heating. The objective of the research to find the right activation time and temperature in order to get a high quality of active charcoal that met the criteria of national standard. The research was done using complete random design with factorial testing. Variables of the research were activation time and temperature. The temperature was varied in four different variables: $700,800,900$, and $1000^{\circ} \mathrm{C}$, while the activation time consisted of four variables: 1, 2, 3 and 4 hours. The result was measured for their lodine absorption, water content, and ash content. The result of the research through high temperature heating showed that the best wood charcoal could be obtained by 4 hours heating at $800^{\circ} \mathrm{C}$. The result had characteristics that met the standard criteria of SNI 06-3730-1995. It had 806,00 mg/g lodine's absorption, $0.82 \%$ water content and $1.35 \%$ ash content.
\end{abstract}

\section{Keywords: Charcoal activation, active charcoal, laban wood}

\section{PENDAHULUAN}

Pada era industrialisasi Indonesia sekarang, peranan arang aktif semakin meningkat karena banyaknya industriindustri yang berkembang menggunakan bahan tersebut. Industri pengolahan air, makanan, farmasi, dan berbagai industri kimia sangat membutuhkan arang aktif dalam proses pengolahannya. Akan tetapi sejauh ini kebutuhan arang aktif dalam negeri masih dipenuhi dari impor (Hartoyo et al, 1990). Hal ini disebabkan kurang tersedianya peralatan dan proses aktivasi 
arang dengan menggunakan teknologi yang tepat guna, murah dan praktis, walaupun mempunyai bahan baku newable yang cukup potensial.

Sejauh ini salah satu bahan baku renewable arang aktif yang banyak digunakan adalah kayu laban. Kayu Laban (Vitex pubescens VAHL) dan (Vitex pinnata $L$ ) adalah salah satu jenis tanaman hutan dengan sebaran pertumbuhan hampir di seluruh Indonesia, meliputi Jawa, Madura, Sumatera, Kalimantan, Sulawesi, dan Pulau Bangka. Kayu laban merupakan jenis pohon yang mudah tumbuh dan dapat ditanam pada berbagai jenis tanah, memiliki daya tahan terhadap kebakaran dan banyak tumbuh di hutan sekunder. Pada tahun 1994 tanaman laban telah dibudidayakan oleh Pusat Pengembangan Teknologi Arang Terpadu diatas tanah seluas 1,4 $\mathrm{Ha}$, sehingga sejak tahun 1997 telah berproduksi yang dimanfaatkan sebagai bahan baku arang. Sedangkan di Kalimantan Barat sampai saat ini telah dikembangkan pembudidayaan kayu laban di empat kabupaten yaitu Kabupaten Ketapang, Kabupaten Pontianak, Kabupaten Sintang dan Kabupaten Sanggau.

Arang adalah bahan padat yang berpori-pori dan merupakan hasil pembakaran dari bahan yang mengandung unsur karbon. Sebagian besar pori-pori tersebut masih tertutup oleh hidrokarbon dan senyawa organik lain, sehingga daya serapnya rendah. Komponen-komponen arang tersebut terdiri dari zat mudah menguap, abu, air, nitrogen dan sulfur (Manarsip et al, 1996). Sedangkan arang aktif adalah karbon non grafit yang dapat dihasilkan dari semua bahan yang mengandung karbon seperti batubara, kayu, sekam padi, tempurung kelapa dan sebagainya (Anonimous, 2006).

Menurut Manalu (2013) bahwa arang aktif merupakan senyawa karbon amorf dan sebagian besar terdiri dari karbon bebas, yang dapat dihasilkan dari bahan-bahan yang mengandung karbon atau dari arang dengan perlakuan secara khusus untuk mendapatkan permukaan yang lebih luas. Arang aktif mempunyai sifat fisika antara lain berwarna hitam, tidak berbau, tidak berasa dan mempunyai banyak rongga. Luas rongga tersebut menjadi parameter penting dalam peningkatan daya serap. Arang aktif mempunyai luas permukaan 300 sampai 2000 m2 per gram. Karakteristik bahan karbon aktif seperti ukuran pori dan partikel, luas permukaan, permukaan kimia, kerapatan dan kekasaran sangat berpengaruh terhadap efisiensi penyerapan (Baksi etal., 2004).

Proses aktivasi arang dapat dibedakan menjadi tiga jenis, yaitu proses aktivasi fisika, kimia, dan proses campuran (Pari dkk, 1996). Pada aktivasi fisika proses pemutusan rantai karbon dari senyawa organik dilakukan dengan bantuan panas atau uap atau $\mathrm{CO}_{2}$, sedangkan pada aktivasi kimia dan aktivasi campuran adalah dengan penggunaan bahan kimia pengaktif (aktivator) disamping bantuan pemanasan (Anonimous, 2012 dan Manalu, 2013). Walaupun suhu aktivasi kimia dan campuran dapat berlangsung lebih rendah dari pada aktivasi fisika, namun terjadinya pencemaran lingkungan tidak dapat dihindari (Nurhayati dan Syahrir, 1997).

Pada aktivasi kimia dan campuran tersebut, bahan kimia pengaktif akan masuk di antara sela-sela lapisan karbon heksagonal dan selanjutnya membuka permukaan yang tertutup (Bansal et.al.,1988). Selanjutnya saat proses pengarangan senyawa-senyawa kimia tersebut akan terurai, sehingga menyebabkan pencemaran lingkungan (Anonimous, 2012 dan Manalu, 2013). Berdasarkan hal tersebut maka proses aktivasi yang ramah lingkungan adalah proses fisika menggunakan suhu tinggi.

Proses aktivasi fisika secara pemanasan pada suhu $800-1000^{\circ} \mathrm{C}$ yang kemudian didinginkan pada atmosfer inersial dapat menghasilkan jenis arang aktif dengan permukaan bersifat basa. Jenis arang aktif ini efektif mengadsopsi senyawa-senyawa kimia organik, partikulat hidrofobik, dan senyawa-senyawa kimia yang sulit larut dalam air. Dengan demikian memungkinkan untuk membantu kecukupan kebutuhan arang aktif untuk pabrik minyak makan dan penjernihan air, karena spesifikasi arang aktifnya yang sesuai (Anonimous, 2012 dan Manalu, 2013).

Aktivasi fisika menggunakan suhu tinggi adalah suatu perlakuan terhadap arang pada suhu yang tinggi dengan tujuan 
memperbesar pori-pori arang (Rio et al, 2005). Menurut Ferry (2002), Anonimous, (2012) dan Manalu (2013) bahwa pembuatan arang aktif secara fisika dengan suhu tinggi mencakup tiga tahap utama yaitu proses dehidrasi, karbonisasi dan aktivasi. Dehidrasi adalah proses menghilangkan air terhadap bahan baku dengan cara memanaskan sampai suhu $170^{\circ} \mathrm{C}$. Karbonisasi merupakan penguraian selulosa dan pengeluaran unsur-unsur non karbon yang berlangsung pada suhu sekitar $(600-700)^{\circ} \mathrm{C}$. Pengarangan atau karbonisasi kayu dapat dilakukan dengan menggunakan drum. Setelah kayu habis terbakar, drum segera ditutup menggunakan kain/terpal basah agar pengarangan tidak berlanjut dengan pengabuan (Ponten, 1991).

Menurut Steve dan Erika, (2005) bahwa proses dehidrasi dan karbonisasi yang baik adalah menggunakan pemanasan lambat pada kondisi tanpa udara. Sedangkan aktivasi adalah dekomposisi tar dan perluasan pori-pori dengan cara memecahkan ikatan hidrokarbon atau mengoksidari molekul-molekul permukaan menggunakan suhu tinggi, sehingga arang mengalami perubahan sifat, baik kimia maupun fisika, seperti pertambahan luas permukaan yang berpengaruh terhadap daya adsorpsi. Makin tinggi suhu yang digunakan, maka semakin baik daya serapnya, tetapi tidak boleh melebihi $1000^{\circ} \mathrm{C}$. Hal ini dikarenakan akan terbentuk abu makin besar, yang memungkinkan menutupi pori-pori, sehingga menghambat daya adsopsi menyebabkan daya serapnya menurun (Anonimous, 2012).

Dalam mengukur kinerja penelitian arang aktif dapat menggunakan Standar Nasional Indonesia (SNI) No. 06-3730-1995. Persyaratan mutu arang aktif yang ditetapkannya antara lain memiliki daya serap lodium minimum 750 mg/g dan kadar air maksimum 15 persen. Selain itu juga kadar abu maksimum 10 persen untuk arang aktif berbentuk serbuk.

Berdasarkan hal tersebut diatas serta mengingat potensi kayu laban renewable yang cukup potensial di Indonesia, khususnya Kalimantan, maka penelitian aktivasi arang aktif menggunakan suhu tinggi terhadap kayu laban tersebut cukup diperlukan. Proses aktivasi ini disamping ramah terhadap lingkungan juga memungkinkan dapat membantu kecukupan bahan pembantu arang aktif terhadap industri daerah lokasi. Karena itu penelitian ini bertujuan untuk mendapatkan kondisi suhu dan waktu aktivasi menggunakan suhu tinggi yang baik agar dapat dihasilkan arang aktif dengan mutu yang memenuhi persyaratan standar.

\section{METODOLOGI PENELITIAN}

Bahan yang digunakan adalah kayu laban (Vitex pubescens VAHL) yang diperoleh dari hasil budidaya PPAT Yayasan Dian Tama Toho Kabupaten Pontianak. Selain itu juga air dan minyak tanah.

Peralatan yang diperlukan adalah drum pengarangan, alat penumbuk dari besi tuang, ayakan 18 dan 40 mesh, dan peralatan untuk pengujian.

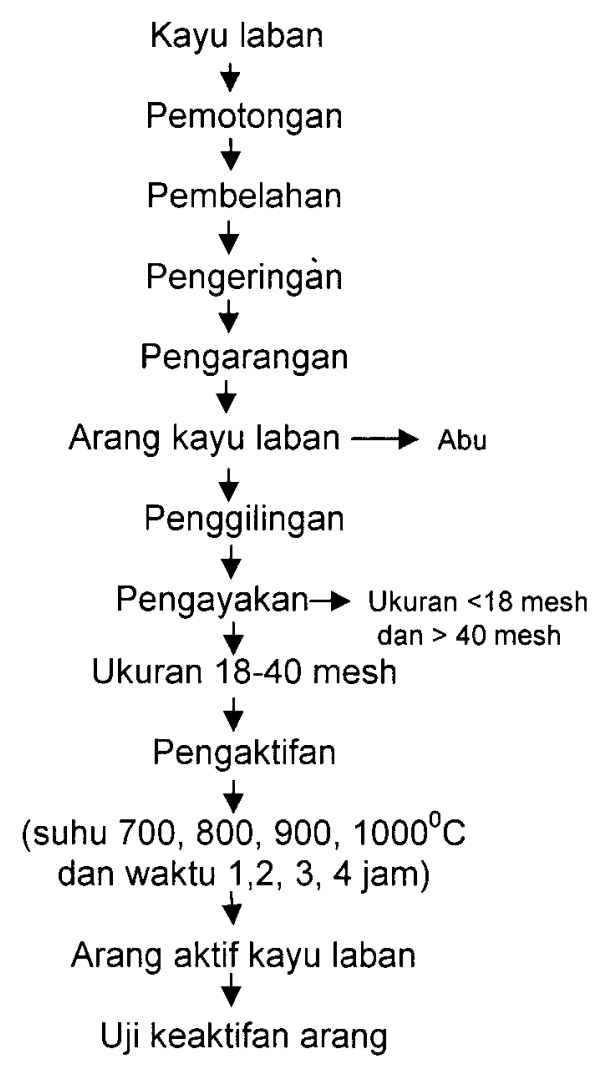

Gambar 1. Tahap-tahap proses pengolahan arang aktif kayu laban secara fisik menggunakan suhu tinggi (Anonimous, 2012 dan Manalu, 2013). 
Proses aktivasi arang kayu laban diawali dari kayu laban (diameter $\pm 10 \mathrm{~cm}$ ) dipotong-potong dengan panjang $\pm 20 \mathrm{~cm}$ dan dibelah menjadi empat bagian. Dikeringkan sampai kering udara (kadar air $\pm 10 \%$ ). Selanjutnya disusun dalam drum pengarangan, disiram minyak tanah sedikit untuk penyalaan awal. Dibakar hingga terjadi karbonisasi sempurna, kemudian drum ditutup dengan karung goni yang dibasahi air. Setelah dingin, arangnya diambil dan dikemas dalam kantong plastik. Arang ditumbuk dengan alat penumbuk dan diayak dengan ayakan 18 dan 40 mesh. Butiran arang yang lolos ayakan 18 mesh tetapi tidak lewat 40 mesh yang dipakai untuk penelitian. Butiran arang tersebut dimasukkan ke dalam cawan porselen, kemudian ditutup. Arang di dalam cawan tersebut dimasukkan dalam tanur listrik untuk diaktivasi sesuai perlakuan. Arang aktif yang dihasilkan dikemas dalam kantong plastik dan di label sesuai dengan perlakuan percobaan (Anonimous, 2012 dan Manalu, 2013). Untuk lebih jelasnya tahapan proses pembuatan arang aktif tersebut, dapat dilihat pada Gambar 1.

Untuk mengukur kinerja perlakuan percobaan, dilakukan pengujian terhadap daya serap lodium, mg/g (ASTM, 1999), kadar air (persen) dan kadar abu, persen (Apriyantono et al, 1989).

Rancangan percobaan yang diterapkan adalah rancangan acak Lengkap (RAL) faktorial dengan dua faktor perlakuan yaitu suhu aktivasi $(A)$ terdiri dari $A 1\left(700^{\circ} \mathrm{C}\right)$, $\mathrm{A} 2\left(800^{\circ} \mathrm{C}\right), \mathrm{A} 3\left(900^{\circ} \mathrm{C}\right)$, dan A4 $\left(1000^{\circ} \mathrm{C}\right)$ serta waktu aktivasi $(B)$, terdiri dari B1 (1 jam), B2 ( 2 jam), B3 (3 jam), dan B4 (4 jam). Masing-masing perlakuan diulang tiga kali.

\section{HASIL DAN PEMBAHASAN}

\section{Daya Serap lodium}

Hasil pengujian daya serap lodium arang aktif kayu laban dari berbagai perlakuan suhu dan waktu aktivasi berkisar antara 563,67 mg/g sampai dengan 863,05 $\mathrm{mg} / \mathrm{g}$. Daya serap rata-rata sebesar 700,28 $\mathrm{mg} / \mathrm{g}$, seperti yang dapat dilihat pada Tabel 1.

Hasil analisis statistika menunjukkan bahwa semua perlakuan suhu aktivasi (A) dan perlakuan waktu aktivasi (B) serta perlakuan interaksi ( $A B$ ) sangat mempengaruhi daya serap lodium. Daya serap lodium pada suhu aktivasi $700^{\circ} \mathrm{C}$ adalah paling kecil, daya serap semakin besar, bila suhu aktivasi makin dinaikan; tetapi jumlah kenaikan tersebut cenderung makin mengecil mendekati suhu $1000^{\circ} \mathrm{C}$ (Tabel 1 dan Gambar 2).

Tabel 1. Nilai rata-rata daya serap terhadap lodium (mg/g) arang aktif kayu laban dari berbagai perlakuan percobaan

\begin{tabular}{|c|c|c|c|c|c|}
\hline \multirow[b]{2}{*}{$\begin{array}{l}\text { Suhu } \\
\text { Aktivasi, } \\
{ }^{0} \mathrm{C} \\
\text { (A) }\end{array}$} & \multicolumn{4}{|c|}{ Waktu Aktivasi, jam (B) } & \multirow[b]{2}{*}{$\begin{array}{l}\text { Rata- } \\
\text { rata }\end{array}$} \\
\hline & 1 (B1) & 2 (B2) & $3(\mathrm{~B} 3)$ & $4(B 4)$ & \\
\hline 700 (A1) & 563,67 & 595,32 & 650,00 & 710,50 & $629,87^{w}$ \\
\hline 800 (A2) & 605,00 & 678,34 & 741,00 & 806.00 & $707,59^{x}$ \\
\hline 900 (A3) & 609,33 & 689,33 & 765,00 & 840,04 & $725.93^{y}$ \\
\hline $1000(A 4)$ & 615,83 & 695,04 & 777,05 & 863,05 & $737,74^{2}$ \\
\hline $\begin{array}{l}\text { Rata- } \\
\text { rata }\end{array}$ & $598,46^{a}$ & $664,51^{b}$ & $733,26^{c}$ & $804,90^{d}$ & 700,28 \\
\hline
\end{tabular}

Cat: Angka ekponen yang berbeda pada baris atau lajur yang sama menunjunkkan perbedaan sangat nyata.

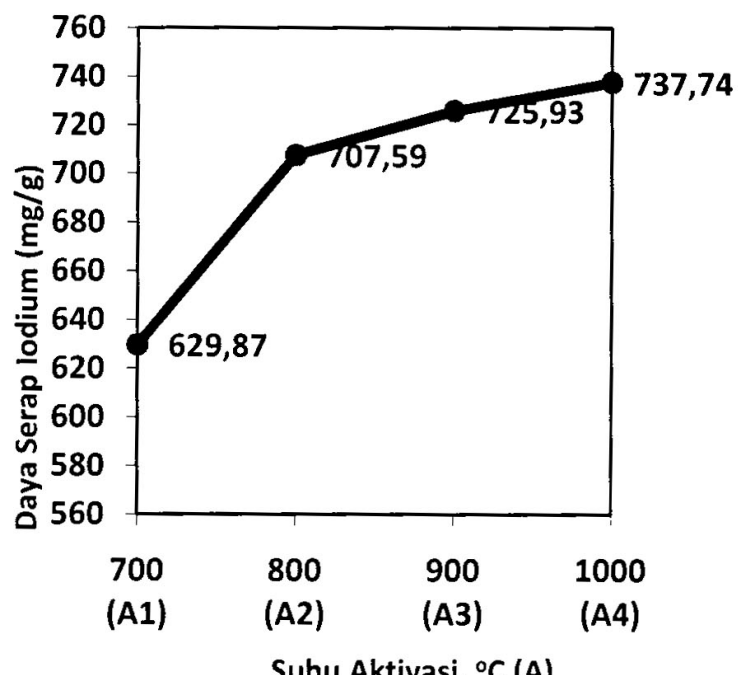

Gambar 2. Pengaruh suhu aktivasi terhadap daya serap lodium arang aktif kayu laban. 
Hal ini dikarenakan makin tinggi suhu aktivasi, maka semakin banyak komponenkomponen penutup pori-pori permukaan arang aktif yang terlepas. Sisa-sisa hidrokarbon yang tertinggal di permukaan arang akan semakin banyak menguap/hilang pada suhu yang semakin tinggi akibat perbedaan titik didih, sehingga permukaan arang aktif akan menjadi lebih luas dan pori-porinya akan lebih terbuka dengan demikian daya serapnya akan menjadi lebih besar. Tetapi mendekati suhu $1000^{\circ} \mathrm{C}$ mulai terbentuk arang, yang akan menutupi pori-pori permukaannya menyebabkan pertambahan daya serap mengecil. Selanjutnya bila suhu ditingkatkan melebihi $1000^{\circ} \mathrm{C}$, malah akan menurunkan daya serapnya, karena pembentukan abu yang makin membesar akan menutupi poripori permukaan arang (Anonimous, 2012).

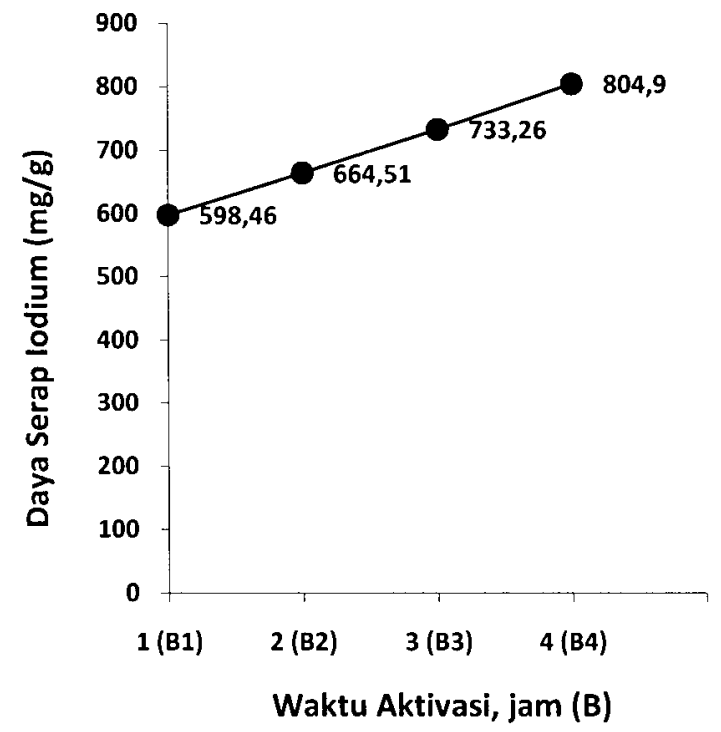

Gambar 3. Pengaruh waktu aktivasi terha dap daya serap lodium arang aktif kayu laban.

Pada Tabel 2 dan Gambar 3 terlihat bahwa dengan menambah waktu aktivasi maka daya serap juga menjadi lebih besar. Hal ini sesuai pendapat Polli dan Fahri (1995) yang menyatakan bahwa semakin lama waktu aktivasi maka daya serap lodium arang aktif dari kayu semakin besar. Kondisi ini terjadi dikarenakan dengan semakin bertambahnya waktu aktivasi, maka ikatan hidrogen dan karbon dalam arang akan terlepas sempurna, sehingga permukaan arang akan menjadi lebih luas dan pori-pori arang aktif akan makin terbuka, dengan demikian maka daya serap arang aktif menjadi lebih besar.

Perlakuan interaksi antara waktu dan suhu aktivasi (Tabel 1) menunjukkan bahwa kombinasi perlakuan yang dapat menghasilkan daya serap lodium arang aktif kayu laban yang memenuhi persyaratan SNI 06-3730-1995 adalah penggunaan suhu aktivasi sebesar $800^{\circ} \mathrm{C}$ selama 4 jam $(806,00$ $\mathrm{mg} / \mathrm{g})$, suhu $900^{\circ} \mathrm{C}$ selama 3 jam $(765,000$ $\mathrm{mg} / \mathrm{g})$, suhu $900^{\circ} \mathrm{C}$ selama 4 jam $(840,04$ $\mathrm{mg} / \mathrm{g})$, suhu $1000^{\circ} \mathrm{C}$ selama 3 jam $(777,05$ $\mathrm{mg} / \mathrm{g}$ ) dan suhu $1000^{\circ} \mathrm{C}$ selama 4 jam $(863,05 \mathrm{mg} / \mathrm{g})$. Diantara kombinasi perlakuan tersebut yang paling optimal adalah penggunaan suhu $800^{\circ} \mathrm{C}$ selama 4 jam. Hal ini mungkin disebabkan karena pada suhu aktivasi $800^{\circ} \mathrm{C}$ selama 4 jam tersebut dapat menyebabkan proses penguraian senyawa komplek menjadi senyawa yang lebih sederhana berlangsung lebih sempurna, sehingga yang tinggal hanya karbon aktif murni. Kondisi ini mengakibatkan luas permukaan yang bersifat aktif lebih besar, sehingga daya serap terhadap lodium menjadi lebih tinggi (Pari et al, 1996 dan BSN, 1995). Selain itu juga dengan penggunaan suhu lebih rendah dan waktu makin lama lebih potensial meningkatkan daya serap lodium arang aktif (ditandai oleh grafik yang cenderung menaik kearah kanan pada Gambar 3) dibandingkan dengan penggunaan suhu lebih tinggi dengan waktu lebih singkat (ditandai oleh grafik yang cenderung berbentuk parabola pada Gambar 2), disamping penggunaan suhu tinggi yang cenderung bersifat lebih korosif.

\section{Kadar Air}

Hasil uji rata-rata kadar air arang aktif kayu laban dari berbagai perlakuan percobaan sebesar 0,65-3,02 persen. Sedangkan kadar air rata-ratanya sebesar 1,56 persen (Tabel2). Hasil analisis statistik menunjukkan bahwa perlakuan suhu aktivasi $(A)$, waktu $(B)$ dan interaksinya $(A B)$ sangat mempengaruhi kadar air arang aktif kayu laban.

Tabel 2. Nilai rata-rata kadar air (persen) 
arang aktif kayu laban dari berbagai perlakuan percobaan

\begin{tabular}{|c|c|c|c|c|c|}
\hline \multirow{2}{*}{$\begin{array}{l}\text { Suhu } \\
\text { Aktivasi, } \\
{ }^{\circ} \mathrm{C} \text { (A) }\end{array}$} & \multicolumn{4}{|c|}{ Waktu Aktivasi, jam (B) } & \multirow[b]{2}{*}{$\begin{array}{l}\text { Rata- } \\
\text { rata }\end{array}$} \\
\hline & 1 (B1) & 2 (B2) & 3 (B3) & 4 (B4) & \\
\hline 700 (A1) & 3,02 & 2,80 & 1,80 & 0,96 & $2,15^{w}$ \\
\hline 800 (A2) & 2,50 & 2,10 & 1,62 & 0,82 & $1,76^{x}$ \\
\hline $900(A 3)$ & 1,80 & 1,60 & 1,50 & 0,73 & $1,41^{y}$ \\
\hline 1000 (A4) & 1,16 & 1.02 & 0,93 & 0,65 & $0,94^{z}$ \\
\hline Rata-rata & $2,12^{a}$ & $1,88^{b}$ & $1,46^{\mathrm{C}}$ & $0,79^{d}$ & 1,56 \\
\hline
\end{tabular}

atau lajur yang sama menunjunkkan perbedaan sangat nyata.

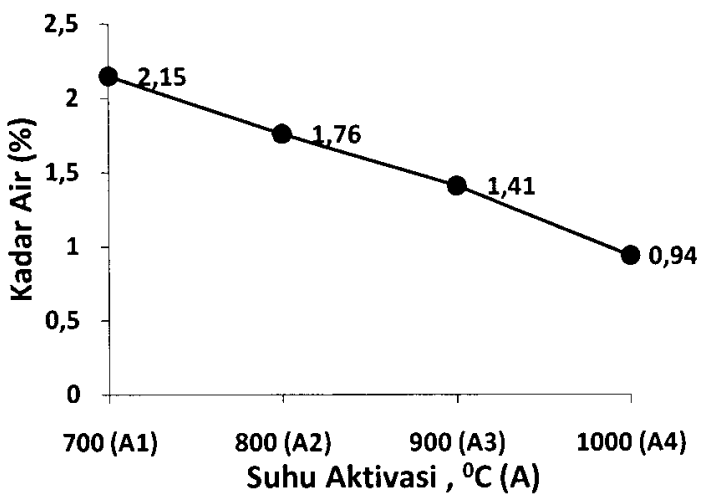

Gambar 4. Pengaruh suhu aktivasi terhadap kadar air arang aktif kayu laban.

Pada Tabel 2 dapat dilihat bahwa kadar air arang aktif yang diaktivasi pada suhu $700^{\circ} \mathrm{C}$ adalah yang paling besar. Makin dinaikkan suhu aktivasinya maka kadar airnya semakin kecil (Gambar 4). Hal ini disebabkan semakin tinggi suhu aktivasi mengakibatkan penguapan air bebasnya makin besar, sehingga memperkecil kadar air arang aktif. Begitu pula dengan waktu aktivasi yang makin lama dan interaksi waktu dengan suhu yang makin lama dan tinggi, menyebabkan kadar airnya makin kecil (Tabel 2 dan Gambar 5). Hal ini karena waktu aktivasi makin lama atau kombinasi waktu dengan suhu makin lama dan tinggi, menyebabkan penguapan jumlah air bebasnya makin besar. Air bebas bagian dalam arang bergerak ke permukaan lalu menguap, sehingga makin dinaikkan suhu aktivasinya dan atau diperpanjang waktunya, maka kadar airnya semakin kecil
(Muchtadi dan Ayustaningwarno, 2010).

Kadar air arang aktif dari semua perlakuan percobaan telah memenuhi persyaratan standar (SNI 06-3730-1995). Karena itu suhu dan waktu aktivasi yang dipilih sesuai dengan kondisi aktivasi untuk parameter daya serap lodium terbaik, yaitu suhu sebesar $800^{\circ} \mathrm{C}$ selama 4 jam, yang menghasilkan kadar air sebesar 0,82 persen.

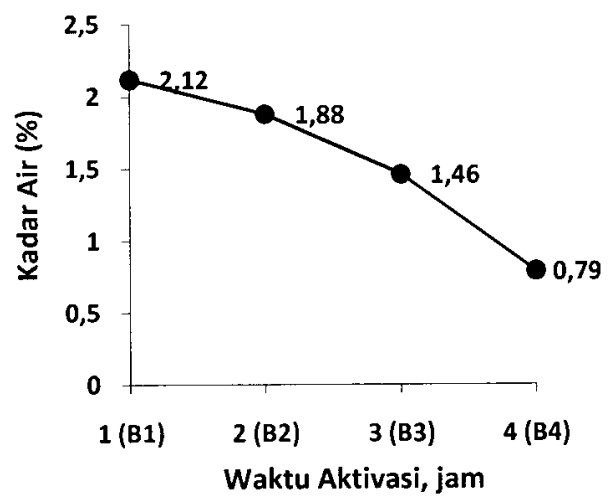

Gambar5. Pengaruh waktu aktivasi terhadap kadar air arang aktif kayu laban.

\section{Kadar Abu}

Hasil uji rata-rata kadar abu arang aktif kayu laban dari berbagai perlakuan percobaan sebesar 0,99-6,02 persen dengan kadar abu rata-rata sebesar 2,41 persen (Tabel 3). Hasil analisis statistik menunjukkan bahwa perlakuan suhu aktivasi $(A)$, waktu $(B)$ dan interaksinya $(A B)$ sangat mempengaruhi kadar abu arang aktif kayulaban.

Kadar abu arang aktif yang diaktivasi pada suhu $700^{\circ} \mathrm{C}$ adalah yang paling besar. Semakin dinaikkan suhu aktivasinya maka kadar abunya semakin kecil (Tabel 3 dan Gambar 6). Hal ini disebabkan semakin tinggi suhu aktivasi mengakibatkan penguraian senyawa komplek yang menutupi pori-pori permukaan arang menjadi senyawa sederhana berlangsung makin sempurna menghasilkan $\mathrm{CO}_{2}$ dan $\mathrm{H}_{2} \mathrm{O}$ yang menguap, sehingga yang tertinggal hanya karbon murni dengan pori-pori yang makin besar.

Tabel3. Nilai rata-rata kadar abu (persen) 
arang aktif kayu laban dari berbagai perlakuan percobaan

\begin{tabular}{|c|c|c|c|c|c|}
\hline $\begin{array}{c}\text { Suhu } \\
\text { Aktivasi, } \\
\text { OC (A) }\end{array}$ & \multicolumn{4}{|c|}{ Waktu Aktivasi, Jam (B) } & Rata- \\
\cline { 2 - 6 } & $\mathbf{1}$ (B1) & $\mathbf{2}$ (B2) & $\mathbf{3}$ (B3) & $\mathbf{4}$ (B4) & \\
\hline 700 (A1) & 6,02 & 4,80 & 2,80 & 1,50 & $3,78^{\mathbf{w}}$ \\
\hline 800 (A2) & 4,50 & 3,10 & 2,02 & 1,35 & $2,74^{\mathbf{x}}$ \\
\hline 900 (A3) & 2,60 & 2,10 & 1,40 & 1,02 & $1,78^{\mathbf{y}}$ \\
\hline 1000 (A4) & 2,00 & 1,35 & 1,06 & 0,99 & $1,35^{\mathbf{z}}$ \\
\hline $\begin{array}{c}\text { Rata- } \\
\text { rata }\end{array}$ & $3,78^{\mathbf{a}}$ & $2,84^{\mathbf{b}}$ & $1,82^{\mathrm{C}}$ & $1,22^{\mathbf{d}}$ & 2,41 \\
\hline \\
Cat: Angka ekponen yang berbeda pada baris atau \\
lajur yang sama menunjukkan perbedaan \\
sangat nyata.
\end{tabular}

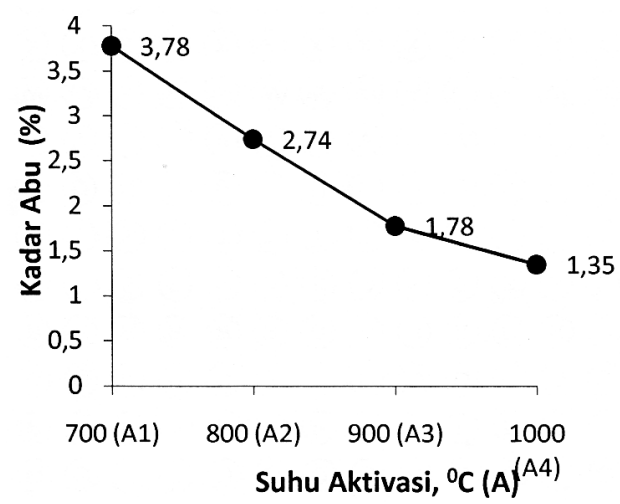

Gambar6. Pengaruh suhu aktivasi terha dap kadar abu arang aktif kayu laban

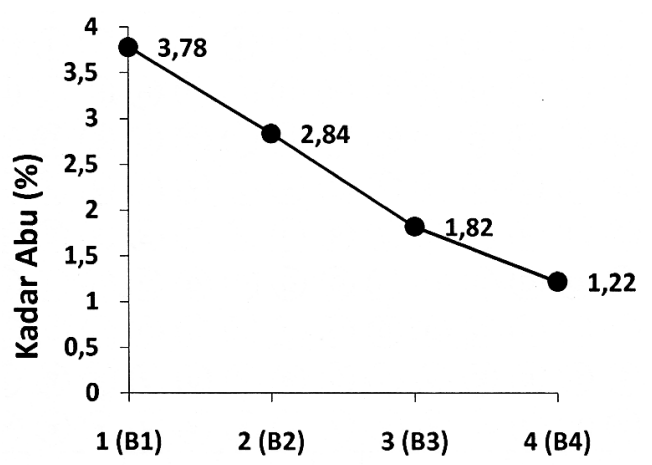

Waktu Aktivasi, jam (B)

Gambar 7. Pengaruh waktu aktivasi terha dap kadar abu arang aktif kayu laban.

Senyawa-senyawa komplek tersebut akan menjadi abu saat suhu aktivasi kurang tinggi dan atau waktu yang lebih kecil, sehingga dengan keberadaannya yang makin kecil akan menurunkan kadar abu arang aktif (Tabel 3). Begitu pula dengan waktu aktivasi yang makin lama dan interaksi waktu dengan suhu yang makin lama dan tinggi, menyebabkan kadar abunya makin kecil (Tabel 3 dan Gambar 7). Hal ini karena waktu aktivasi makin lama atau kombinasi waktu dengan suhu makin lama dan tinggi, menyebabkan penguraian senyawa komplek penutup pori-pori permukaan arang makin sempurna dan yang tertinggal adalah karbon makin murni dengan pori-pori semakin besar, sehingga kadar abunya menjadi makin kecil (Rio et al, 2005).

Kadar abu arang aktif dari semua perlakuan percobaan telah memenuhi persyaratan standar (SNI 06-3730-1995). Karena itu suhu dan waktu aktivasi yang dipilih sesuai dengan kondisi aktivasi untuk parameter daya serap lodium terbaik, yaitu suhu sebesar $800^{\circ} \mathrm{C}$ selama 4 jam, yang memberikan kadar abu sebesar 1,35 persen.

\section{KESIMPULAN DAN SARAN}

\section{Kesimpulan}

Berdasarkan pembahasan tersebut, maka dapat diambil kesimpulan bahwa kondisi proses aktivasi arang kayu laban (Vitex pubescens VAHL) menggunakan suhu tinggi yang cukup baik adalah dengan cara aktivasi pada suhu $800{ }^{\circ} \mathrm{C}$ selama 4 jam. Kondisi proses aktivasi tersebut dapat memberikan daya serap lodium arang aktif kayu laban sebesar $806,00 \mathrm{mg} / \mathrm{g}$, yang memenuhi persyaratan mutu sesuai SNI 063730-1995. Begitu juga mempunyai kadar air sebesar 0,82 persen dan abu sebesar 1,35 persen sesuai persyaratan standar.

\section{Saran}

Untuk mendapatkan proses aktivasi arang kayu laban yang lebih efisien dan efektif, maka perlu dilakukan percobaan aktivasi dengan metoda yang lain, seperti cara kimia atau kombinasi cara kimia dan fisika dengan dilengkapi perhitungan teknoekonomi.

\section{DAFTAR PUSTAKA}


Anonimous. 2006. Activated Chorcoal. http.www.answer.com/topik/activated. carbon. Diakses pada bulan Agustus 2010.

Anonimous. 2012. BMD : Cara Pembuatan A $r$ a $n g \quad A k t i f$. Bmdstreet.com/category/artikel.Diak ses pada bulan September 2013.

Apriyantono, A., Fardiaz, D., Puspitasari, N.L. dan Budianto, S. 1989. Petunjuk Laboratorium Analisa Pangan. Depdikbud Dirjen Pendidikan Tinggi. PAU Pangan dan Gizi IPB. Bogor.

ASTM. 1999. Standard Test Method for Determination of lodine Number of Activated Carbon. American Society for Testing and Material. Philadelphia.

Badan Standadisasi Nasional, 1995, Standar Nasional Industri No. 063730-1995 tentang Syarat Mutu Arang Aktif Teknis, Badan Standardisasi Nasional, Jakarta.

Baksi, S, Soumitra Biswas and S. Mahajan. 2005. Activated Carbon from BamboTechnology Development towards commercialization. Paper of Departement of Chimical engineering of IIT. Bombay.

Bansal, C. R. , J. B. Donnet, and F. Stoeckli. 1988. Active Carbon. Marcel Dekker Inc. New York.

Ferry, J. 2002. Pembuatan Arang Aktif dari Serbuk Gergaji Kayu sebagai Adsorben pada Pemurnian Minyak Goreng Bekas (Skripsi) FMIPA IPB, Bogor

Hartoyo, Hudaya, N, dan Fadli, 1990, Pembuatan dan Kayu Bahan dengan Cara Aktivasi Uap, Jurnal Penelitian Hasil Hutan, Vol. 8.

Manalu, M.S.D. 2013. Arang Aktif. Marischemistry.blogspot.com./2013/ 04/normal-o-false-false-false-en-usx-none.html. Diakses pada bulan Sepember 2013.

Manarsip, J., Petrus., Hendrik T., Venny A.,
Ramly P., Zetly S. 1996. Pengembangan pemanfaatan tempurung Biji Pala sebagai Arang Aktif. Balai Penelitian dan Pengembangan Industri. Manado.

Muchtadi, T.R. dan Ayustaningwarno, F. 2010. Teknologi Proses Pengolahan Pangan. PenerbitAlfabeta. Bandung.

Pari, G., Buchari dan Sulaeman, A., 1996, Pembuatan dan Kualitas Arang Aktif dari Kayu Sengon (Paraserianthes falcataria) sebagai Bahan Adsorban, Buletin Penelitian Hasil Hutan, Vol. 14.

Polli F. dan Fahri. 1995. Batang Kelapa sebagai Bahan Baku Industri Arang Aktif. Majalah IImiah BIMN, No. 8. BPPI Manado.

Ponten M. Naibaho, 1991. Penggunaan Tempurung Kelapa Sawit sebagai Bahan Arang Aktif dengan Metode Karbonisasi. Berita Penelitian Perkebunan, Vol. 1 No. 1 Pusat Penelitian Perkebunan. Medan.

Pari, G., Buchari dan Sulaeman, A., 1996, Pembuatan dan Kualitas Arang Aktif dari Kayu Sengon (Paraserianthes falcataria) sebagai Bahan Adsorban, Buletin Penelitian Hasil Hutan, Vol. 14.

Rio S., Le Coq, L., Faur, C., Le Cloirec, P. 2005. Production of porous carbonaceous adsorbent from physical activation of sewage sludge application to wastewater treatment Nanyang Tecnological University. Singapore.

Steve Kvech dan Erika. 2005. Properties of Actived Carbon file ://F:IHoney \%20 SkripsilActivated\%20Carbon.html. Diakses pada tanggal 15 Oktober 2013. 